\title{
əPotential of Dual-Frequency Radar and Microwave Radiometer Synergy for Water Vapor Profiling in the Cloudy Trade Wind Environment
}

\author{
SABRINA SCHNITT, ${ }^{\mathrm{a}, \mathrm{d}}$ ULRICH LÖHNERT, $^{\mathrm{b}}$ AND RENÉ PREUSKER ${ }^{\mathrm{c}}$ \\ ${ }^{a}$ Institute of Energy and Climate Research, IEK-8: Troposphere, Forschungszentrum Jülich GmbH, Jülich, Germany; \\ ${ }^{\mathrm{b}}$ Institute for Geophysics and Meteorology, University of Cologne, Cologne, Germany; ${ }^{\mathrm{c}}$ Institute for Space Sciences, \\ Freie Universität Berlin, Berlin, Germany
}

(Manuscript received 27 June 2019, in final form 20 July 2020)

\begin{abstract}
High-resolution boundary layer water vapor profile observations are essential for understanding the interplay between shallow convection, cloudiness, and climate in the trade wind atmosphere. As current observation techniques can be limited by low spatial or temporal resolution, the synergistic benefit of combining ground-based microwave radiometer (MWR) and dual-frequency radar is investigated by analyzing the retrieval information content and uncertainty. Synthetic MWR brightness temperatures, as well as simulated dual-wavelength ratios of two radar frequencies are generated for a combination of $\mathrm{Ka}$ and $\mathrm{W}$ band $(\mathrm{KaW})$, as well as differential absorption radar (DAR) G-band frequencies (167 and $174.8 \mathrm{GHz}, \mathrm{G} 2$ ). The synergy analysis is based on an optimal estimation scheme by varying the configuration of the observation vector. Combining MWR and KaW only marginally increases the retrieval information content. The synergy of MWR with G2 radar is more beneficial due to increasing degrees of freedom (4.5), decreasing retrieval errors, and a more realistic retrieved profile within the cloud layer. The information and profile below and within the cloud is driven by the radar observations, whereas the synergistic benefit is largest above the cloud layer, where information content is enhanced compared to an MWR-only or DAR-only setup. For full synergistic benefits, however, G-band radar sensitivities need to allow full-cloud profiling; in this case, the results suggest that a combined retrieval of MWR and G-band DAR can help close the observational gap of current techniques.
\end{abstract}

KEYWORDS: Cumulus clouds; Water vapor; Algorithms; Microwave observations; Radars/Radar observations; Remote sensing

\section{Introduction}

Water vapor is the driving constituent of the global hydrological cycle and of cloud and precipitation formation. It plays a key role in the characterization of the global radiation budget (Held and Soden 2006; Hartmann et al. 2013). In the trades, the maximum variability of atmospheric water vapor is found in the lower part of the troposphere within the boundary layer where it influences shallow convection, cloudiness, and circulation processes (Holloway and Neelin 2009; Sherwood et al. 2010). Thus, precise observations of the low-tropospheric moisture structure in trade wind-driven regions are particularly important to better understand the mechanisms controlling shallow convection, the intensity of cloud feedbacks and, hence, climate sensitivity (Pincus et al. 2018; Nehrir et al. 2017).

Currently, profiles of the atmosphere are available through the operational radiosonde network with ascents typically every 6,12 , or $24 \mathrm{~h}$. However, these observations are not only sparse in temporal and spatial resolution, but also expensive in

¿ Denotes content that is immediately available upon publication as open access.

\footnotetext{
${ }^{\mathrm{d}}$ Current affiliation: Institute for Geophysics and Meteorology, University of Cologne, Cologne, Germany.
}

Corresponding author: Sabrina Schnitt, s.schnitt@uni-koeln.de operation (e.g., Nehrir et al. 2017). Spaceborne sensors provide broad global coverage, but lack the horizontal and vertical resolution needed for quantifying processes in the boundary layer (Ebell et al. 2013; Stevens et al. 2017; Schröder et al. 2019). Ground-based microwave remote sensing instruments are a promising alternative to these methods (Westwater et al. 2004), as the atmosphere is semitransparent in the microwave spectral region. Passive microwave radiometers (MWRs) and radars can, thus, penetrate clouds and measure in clear, cloudy, and, in case of the radar, precipitating conditions. MWRs, such as the Humidity And Temperature Profiler (HATPRO; Rose et al. 2005), accurately provide integrated quantities such as integrated water vapor (IWV) and liquid water path (LWP), and, using the different weighting functions of the channels, can be used for deriving temperature and humidity profiles (Crewell and Löhnert 2007). However, the profiles' vertical resolution, which reaches about $1 \mathrm{~km}$ at $500 \mathrm{~m}$ height, further degrades with height and is too low to accurately quantify the before-mentioned processes. On the other hand, active instrument measurements, such as by the lidar or radar, are characterized by high vertical resolutions, but need backscattering targets like aerosols or cloud droplets to gain information about the profile of the atmosphere. In case of the lidar, a profile can only be derived below cloud base, as the signal is saturated within the cloud layer.

Compensating for disadvantages of each individual instrument, synergistic retrieval approaches that combine passive and active remote sensing instruments increase the information content about the state of the atmosphere (e.g., Stankov 1998; 
Löhnert et al. 2001; Wagner et al. 2019). Synergistic groundbased water vapor retrievals have thus far been developed using the combination of various remote sensing instruments: e.g., MWR and lidar (Barrera-Verdejo et al. 2016; Foth and Pospichal 2017), infrared hyperspectrometer and MWR (Turner and Löhnert 2014), or MWR, ceilometer, and Ka-band radar (Löhnert et al. 2004). Optimal estimation-based retrieval algorithms provide the necessary framework for data evaluation (Rodgers 2000).

The potential of dual-frequency radar for water vapor profiling has been previously explored using the difference in water vapor continuum absorption (Ellis and Vivekanandan 2011; Tian et al. 2007), and frequencies in the $183.31 \mathrm{GHz}$ band (Battaglia and Kollias 2019; Battaglia et al. 2014). Analog to the differential absorption lidar (DIAL) technique, differential absorption radar (DAR) uses one radar frequency close to the absorption line's center (online), and a second frequency on the complex's wing (offline). Evaluating the dual-wavelength ratio (DWR), i.e., the difference between the logarithmic equivalent reflectivity factors, gives information about the partial integrated water vapor amounts along the ray path. Due to the difference of water vapor attenuation in the two frequencies, the partial water vapor amount can be derived between radar and the backscattering volumes (Lebsock et al. 2015; Millán et al. 2016). Only recently, Roy et al. (2020) presented the Vapor In-Cloud Profiling Radar (VIPR), the first ground-based DAR system operating at 167 and $174.8 \mathrm{GHz}$ along the wing of the $183.31 \mathrm{GHz}$ absorption line. With the VIPR system, the water vapor profile throughout the cloud layer can be retrieved with an uncertainty of smaller than $1 \mathrm{~g} \mathrm{~m}^{-3}$.

In this paper, we assess the synergistic benefits of a combined retrieval of dual-frequency radar and MWR for a typical trade wind-driven cloud scene. We analyze a combination of synthetic ground-based MWR K-band brightness temperatures (TBs) with simulated differential radar signals for two frequency pairs: the Ka- and W-band frequencies at 35.5 and $94 \mathrm{GHz}$, later referred to as $\mathrm{KaW}$, which are available at, e.g., the Barbados Cloud Observatory (BCO; Stevens et al. 2016); and a hypothetical G-band frequency combination motivated by the novel VIPR instrument with frequencies at 167 and $174.8 \mathrm{GHz}$, in the following referred to as $\mathrm{G} 2$. The resulting DWR of these two frequency pairs is mainly affected by different absorption features due to their location in the microwave spectrum. In case of $\mathrm{KaW}$, the DWR signal is driven by differential continuum absorption, including contributions due to water vapor as well as liquid water; in case of G2, the signal is mainly affected by the difference in absorption strength on the absorption line wing at $183.31 \mathrm{GHz}$.

As observations of both frequency pairs are not available for simultaneous cases, we use synthetic observations generated by the Passive and Active Microwave Transfer model (PAMTRA; Mech et al. 2020). Specifically, we simulate radar reflectivities at $\mathrm{Ka}, \mathrm{W}$, and $\mathrm{G} 2$ frequencies, as well as of the MWR TBs in the seven HATPRO K-band channels distributed between 22.24 and $31.4 \mathrm{GHz}$. Then, we apply an optimal estimation algorithm to these observations to retrieve the column water vapor profile as well as the LWP. To assess the synergistic benefits of this novel approach, we vary the constellation of the observation vector using MWR-only TBs; radar-only DWRs; and the combination of both. DWR is analyzed for both $\mathrm{KaW}$ and $\mathrm{G} 2$ frequency pairs. In all configurations, a $2 \mathrm{~m}$ humidity observation is used to constrain the retrieval. The synergistic benefit is evaluated based on the total degrees of freedom of signal (DFS; Rodgers 2000) and the resulting retrieval error, and compared to the results of the MWR-only and radar-only retrieval.

The paper is organized as follows: The instruments, the simulation method, and the retrieval concept are introduced in section 2. The synthetic observations, their sensitivity to varying water vapor and liquid water conditions, as well as limitations due to radar detection thresholds are presented in section 3. Based on a typical case study example, we analyze the synergistic retrieval potential in section 4. Expanding the results of the case study to a larger number of scenes, section 5 quantifies the synergistic benefits compared to the MWR-only and radar-only retrievals, underlining differences between the two radar frequency pairs. Furthermore, sensitivities to assumed observation and forward model uncertainties are analyzed, and the impacts of radar sensitivity thresholds on the retrieval are discussed. Section 6 summarizes the findings, and gives an outlook on future application potential of this novel approach.

\section{Synergy concept and algorithm methodology}

\section{a. Instruments and observation simulations}

Exposed to the North Atlantic trade winds, BCO is located at the eastern point of the Barbados island (Stevens et al. 2016). Observing trade wind clouds since 2010, the observatory is equipped with a suite of state-of-the art remote sensing instruments, including a W-band radar recently complementing the suite.

The microwave radiometer HATPRO measures incoming radiation in 14 channels distributed throughout the lower microwave spectrum. In this work, we use the brightness temperature of the 7 water vapor sensitive K-band channels. Six of these channels are located in the center and on the wing of the water vapor absorption line at $22.24 \mathrm{GHz}$. IWV and LWP can be retrieved when including the measurements of a window channel located at $31.4 \mathrm{GHz}$. As the opacity of the atmosphere increases toward the absorption line center, the K-band HATPRO TBs can also be used for humidity profiling, such as described in, e.g., Löhnert et al. (2009). Water vapor profiles can be retrieved with an uncertainty of about $1 \mathrm{~g} \mathrm{~m}^{-3}$, a temporal resolution of 2-4s, and a vertical resolution of $1-2 \mathrm{~km}$, degrading with height. Two to three independent pieces of information can be derived. Due to the limited vertical resolution of the retrieved profile, retrievals based on only MWR observations are not able to resolve strong humidity gradients typical for the trade wind-driven atmosphere observed, e.g., at BCO.

Cloud radars can profile the atmosphere reaching increased vertical resolutions. One of the measured quantities, the equivalent radar reflectivity factor $Z_{e}$ (further referred to as reflectivity), depends on the scatterer's diameter to the power of six when Rayleigh scattering only is assumed. The observed 
$Z_{e}$ is further affected by two-way attenuation due to gas and hydrometeor extinction along the beam path. Microwave attenuation is frequency dependent: liquid water and water vapor attenuation generally increase with frequency (continuum absorption), and attenuation due to water vapor is particularly enhanced within the water vapor absorption lines around 22.24 and $183.31 \mathrm{GHz}$. Further attenuation can occur due to other atmospheric gases like oxygen and nitrogen, which, in the $\mathrm{G}$ band, is smaller than the attenuation due to water vapor. Attenuation is also influenced by the broadening of the absorption lines due to temperature and pressure changes.

The DAR technique, in analogy to the DIAL technique, makes use of the frequency dependent difference in radar attenuation described by the dual-wavelength ratio (DWR $[\mathrm{dB}]=\mathrm{Ze}_{1}[\mathrm{~dB} z]-\mathrm{Ze}_{2}[\mathrm{~dB} z]$ ) when locating one frequency near the absorption line center (online) and one on the absorption line wing (offline). According to Lebsock et al. (2015) and Millán et al. (2016), the differential signal can be related to the amount of water vapor located between the radar and the target when neglecting multiple scattering; assuming that water vapor absorption is order of magnitudes stronger than absorption due to other gases; and when neglecting the temperature and pressure dependency. However, this relation is only valid if non-Rayleigh scattering either does not impact the reflectivity signal, or if it impacts $Z_{e}$ of both frequencies the same way. The former we can assume for the pure liquid clouds observed at BCO in case of the MWR and KaW signals; the latter we assume for the frequencies used in the $G$ band.

Whereas typical Ka-band radars are pulsed radar systems, W-band radar systems typically are nonpulsed frequency modulated continuous wave (FMCW) radars (see, e.g., Küchler et al. 2017). Due to the FMCW principle, the vertical resolution, sensitivity, and Nyquist velocity are height dependent and can be adjusted through the chirp table settings. At BCO, these settings are chosen such that the range bins of the two radar systems match with a vertical resolution of $30 \mathrm{~m}$ throughout the boundary layer. With this range resolution, the pulsed Ka-band radar system reaches a sensitivity threshold of $-69 \mathrm{~dB} z$ at $1 \mathrm{~km}$ height (Görsdorf et al. 2015). Typical W-band settings at BCO lead to a detection threshold of $-51 \mathrm{~dB} z$ at $1000 \mathrm{~m}$, operating with an integration time of $0.9 \mathrm{~s}$.

Roy et al. (2020) present the first operational G-band DAR system and a least squares inversion method to derive the water vapor profile throughout the cloud layer. With a system output power of $0.2 \mathrm{~W}$, a range resolution of $15 \mathrm{~m}$ and a nominal chirp duration time of $1 \mathrm{~ms}$, VIPR reaches a singlepulse reflectivity detection threshold of $-40 \mathrm{~dB} z$ at $1000 \mathrm{~m}$. Decreasing the vertical range resolution to $150 \mathrm{~m}$ would lead to a sensitivity improvement of $10 \mathrm{~dB}$ to $-50 \mathrm{~dB} z$ (R. Roy 2020, personal communication). Noncoherent signal processing would similarly improve the detection sensitivity while decreasing the temporal resolution.

Using the profiling capabilities of the dual-frequency radar, as well as the advantages of the MWR, a synergy concept such as illustrated in Fig. 1 promises increasing information content compared to an MWR-only or radar-only retrieval setup. In the instrument synergy, the MWR provides information about

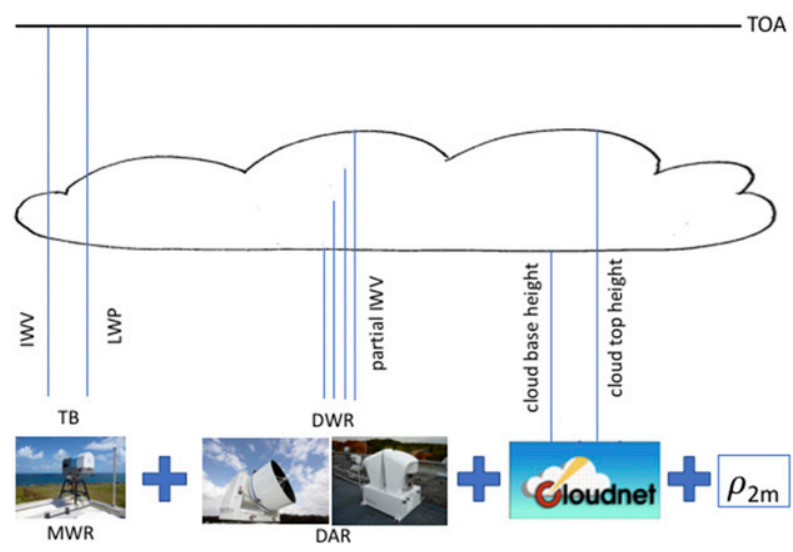

FIG. 1. Concept, instruments, and their observations used in the synergistic retrieval approach: MWR brightness temperature TB for IWV, LWP, and coarse water vapor profile; DWR for partial IWV quantification below cloud base and in-cloud profiling; cloudbase and cloud-top heights provided by, e.g., Cloudnet (Illingworth et al. 2007); and $2 \mathrm{~m}$ humidity observations $\left(\rho_{2 \mathrm{~m}}\right)$. Blue lines represent the vertical range of the instruments' observations.

the full-column water vapor path, the LWP, and a coarse water vapor profile throughout the whole atmospheric column. The dual-frequency radar observations provide information about the partial water vapor amounts between each backscattering volume. Thus, the amount of partial water vapor located between ground and cloud base can be derived, as well as a finely resolved water vapor profile within the cloud layer. In this retrieval approach, we assume that cloud-base and cloud-top height observations and $2 \mathrm{~m}$ humidity observations $\left(\rho_{2 \mathrm{~m}}\right)$ are available, for example, through Cloudnet observations, and use this extra information to constrain the retrieval.

We present a feasibility study based on simulated observations to test the retrieval concept under ideal conditions, as simultaneous observations of all considered instruments are not available. By simulating the instruments' observations, unknown instrument uncertainties or biases of real observational data are eliminated, and a fair comparison between all different retrieval setups and both frequency pairs is possible. The radiative transfer model PAMTRA is used to simulate MWR TBs and radar reflectivity factor $Z_{e}$. To model a typical single-layered liquid trade wind cumulus cloud scenario, we use quality-controlled pressure, temperature, and relative humidity profiles of the 0000 and 1200 UTC radiosondes launched at Grantley Adams International Airport (http:// weather.uwyo.edu/upperair/sounding.html), approximately $15 \mathrm{~km}$ southwest of BCO. We only consider soundings that reached $20 \mathrm{~km}$ altitude, and have complete pressure, temperature, and humidity profiles. The lowest available humidity measurement of each radiosonde profile is assumed as $2 \mathrm{~m}$ humidity observation.

Specifically, we assign a LWP of $50 \mathrm{~g} \mathrm{~m}^{-2}$ to the cloud layer as motivated from previous studies analyzing the distribution of LWP in trade wind-driven conditions around Barbados (see, e.g., Jacob et al. 2019; Schnitt et al. 2017). Due to the high subadiabaticity of these clouds (e.g., Abel and Shipway 2007), 
TABLE 1. Characteristics of observations. The observations forming the OE observation vector are highlighted in boldface print with their corresponding units in parentheses. Radar sensitivity thresholds are given at $1 \mathrm{~km}$ height for a $30 \mathrm{~m}(\mathrm{Ka}, \mathrm{W})$ and $150 \mathrm{~m}(\mathrm{G} 2)$ vertical resolution, and an integration time of $0.9 \mathrm{~s}(\mathrm{~W})$ and $1 \mathrm{~ms}(\mathrm{G} 2)$, respectively.

\begin{tabular}{|c|c|c|c|c|c|c|}
\hline \multirow{4}{*}{$\begin{array}{l}\text { Channels }(\mathrm{GHz}) \\
\text { Measurement }\end{array}$} & \multirow[b]{2}{*}{ MWR HATPRO } & \multicolumn{4}{|c|}{ Dual-frequency radar } & \multirow{2}{*}{$2 \mathrm{~m}$ humidity } \\
\hline & & \multirow{2}{*}{$\begin{array}{c}\mathrm{Ka} \\
35.5\end{array}$} & \multirow{2}{*}{$\begin{array}{c}\mathrm{W} \\
94.0\end{array}$} & \multicolumn{2}{|c|}{ G2 } & \\
\hline & $22.24,23.44,23.84,25.44,26.24,27.84,31.4$ & & & 167.0 & 174.8 & \\
\hline & Brightness temperature TB $(\mathrm{K})$ & \multicolumn{4}{|c|}{$\begin{array}{l}\text { Equivalent reflectivity factor } Z_{e}(\mathrm{~dB} z) \\
\text { Dual-wavelength ratio DWR (dB) }\end{array}$} & $\rho_{2 m}\left(g^{-3}\right)$ \\
\hline Uncertainty & $0.4 \mathrm{~K}$ & \multicolumn{4}{|c|}{$\Delta Z_{e}=0.4 \mathrm{~dB} ; \Delta \mathrm{DWR}=0.56 \mathrm{~dB}$} & $10 \%$ \\
\hline Sensitivity $1 \mathrm{~km}$ & & $-69 \mathrm{~dB} z$ & $-51 \mathrm{~dB} z$ & & & \\
\hline
\end{tabular}

we distribute the LWP such that the liquid water content (LWC) is constant with $0.05 \mathrm{~g} \mathrm{~m}^{-3}$ throughout the cloud layer. Simulating typical cloud conditions observed at BCO (e.g., Nuijens et al. 2014), cloud-base and cloud-top height are assumed to be 1000 and $2000 \mathrm{~m}$, respectively. We assume a cloud droplet effective radius $\left(r_{\text {eff }}\right)$ of $10 \mu \mathrm{m}$, and a lognormal droplet size distribution (DSD) with a shape parameter $\sigma$ of 0.3 (Miles et al. 2000). Using this simplified approach, we neglect potential challenges due to non-Rayleigh scattering of drizzle or ice particles affecting the radar observations. The sensitivity of our results to the assumed cloud parameters is analyzed in section $5 b$.

To model expected measurement uncertainties, we add a random Gaussian noise to each simulated measurement. We assume a TB accuracy of $0.4 \mathrm{~K}$ for all seven K-band channels taking into account uncertainties due to radiometric noise and calibration (Maschwitz et al. 2013). For the radar reflectivities, we assume an uncertainty of $0.4 \mathrm{~dB}$ for all frequencies and heights, based on the errors given by the Cloudnet algorithm (Illingworth et al. 2007) in comparable situations. All considered measurements and their assumed characteristics are summarized in Table 1.

\section{b. Optimal estimation methodology}

Finding a solution to linking an atmospheric state $\mathbf{x}$ to a remote sensing measurement $\mathbf{y}$ by $\mathbf{x}=F^{-1}(\mathbf{y})$ is typically an ill-posed problem. Hence, multiple atmospheric states $\mathbf{x}$ can lead to the same observation $\mathbf{y}$. Bayes's theorem manifests a general way of finding the most probable solution considering $\mathbf{y}$ and a given prior state. The optimal estimation equations derived by Rodgers (2000) fulfill this theorem, assuming a moderately nonlinear forward function $F(\mathbf{x})$, and given that the uncertainties of $\mathbf{x}$ and $\mathbf{y}$ follow a Gaussian distribution. The prior state $\mathbf{x}_{a}$ and its covariance matrix $\mathbf{S}_{a}$ constrain the solution in state space while the solution is physically consistent: applying the forward function to the retrieved state $\mathbf{x}$ leads to the original observation $\mathbf{y}$ within the corresponding measurement uncertainties given by the error covariance matrix $\mathbf{S}_{e}$ and the prior covariance matrix $\mathbf{S}_{a}$.

The optimal solution $\mathbf{x}_{\mathrm{op}}$ is found when iterating Eq. (1) until a minimum of the cost function is found and convergence is reached:

$$
\begin{aligned}
\mathbf{x}_{i+1}= & \mathbf{x}_{a}+\left\{\mathbf { S } _ { a } \mathbf { K } _ { i } ^ { \mathrm { T } } \cdot ( \mathbf { K } _ { i } \mathbf { S } _ { a } \mathbf { K } _ { i } ^ { \mathrm { T } } + \mathbf { S } _ { e } ) ^ { - 1 } \cdot \left[\mathbf{y}-F\left(\mathbf{x}_{i}\right)\right.\right. \\
& \left.\left.+\mathbf{K}_{i} \cdot\left(\mathbf{x}_{i}-\mathbf{x}_{a}\right)\right]\right\} .
\end{aligned}
$$

The Jacobian matrix $\mathbf{K}_{i}$ gives the sensitivity of each observation to each changing state, and is calculated per retrieval iteration:

$$
\mathbf{S}_{i}=\mathbf{S}_{a}-\mathbf{S}_{a} \mathbf{K}_{i}^{\mathrm{T}} \cdot\left(\mathbf{S}_{e}+\mathbf{K}_{i} \mathbf{S}_{a} \mathbf{K}_{i}^{\mathrm{T}}\right)^{-1} \cdot \mathbf{K}_{i} \mathbf{S}_{a}
$$

The diagonal elements of the a posteriori retrieval error matrix $\mathbf{S}_{\text {op }}$ give the uncertainty of each retrieved state, and depend on the prior covariances $\mathbf{S}_{a}$, the Jacobian matrix $\mathbf{K}_{i}$, and the error covariances $\mathbf{S}_{e}$. Here, $\mathbf{S}_{e}$ includes uncertainties from observations, as well as the forward model parameters.

Retrieval convergence requires the residuum of $\mathbf{y}_{\mathbf{i}+1}-\mathbf{y}_{i}$ to be an order of magnitude smaller than the estimated error given by the a posteriori covariance matrix $\mathbf{S}_{\mathrm{op}}$ of the derived state $\mathbf{x}_{\mathrm{op}}$ [Eq. (2)]. Whether the converged solution $\mathbf{x}_{\mathrm{op}}$ is physically consistent can be tested with a $\chi^{2}$ test (e.g., Rodgers 2000; Ebell et al. 2017). A true test verifies, here with a significance level of $95 \%$, that the null hypothesis cannot be rejected. In other words, true convergence is reached if the distribution of the difference $\delta_{\mathbf{y}}$ between forward-modeled retrieval results $F\left(\mathbf{x}_{\mathrm{op}}\right)$ and original observations $\mathbf{y}_{\mathrm{obs}}$ is a member of a Gaussian distribution with zero mean and covariance of $\mathbf{S}_{\delta_{\mathbf{y}}}=\mathbf{S}_{e} \cdot\left(\mathbf{K} \mathbf{S}_{a} \mathbf{K}^{\mathrm{T}}+\mathbf{S}_{e}\right)^{-1} \cdot \mathbf{S}_{e}$.

The averaging kernel matrix $\mathbf{A}$ describes the sensitivity of the retrieved state $\mathbf{x}_{\mathrm{op}}$ to the original state following $\mathbf{A}_{i}=\mathbf{S}_{i}\left(\mathbf{K}_{i}^{\mathrm{T}} \mathbf{S}_{e}^{-1} \mathbf{K}_{i}\right)$. The diagonal elements of $\mathbf{A}$ provide the DFS, that is the independent pieces of information, per retrieved state element; the trace of $\mathbf{A}$ gives the total DFS, describing the total information content available in the retrieval.

In the presented retrieval approach, the state vector $\mathbf{x}$ consists of absolute humidity on 45 height levels with decreasing vertical resolution, and the LWP. We retrieve the natural logarithm of the absolute humidity in order to maintain a quasi-Gaussian distribution of the retrieval states $\mathbf{x}$, such as proposed by Maahn et al. (2020). The retrieved LWP is used to calculate the liquid attenuation of the radar signal in each retrieval iteration. In this paper, the observation vector $\mathbf{y}$ comprises the seven HATPRO K-band brightness temperatures, complemented by the $2 \mathrm{~m}$ humidity observation, as well as the DWR calculated in each layer within the cloud boundaries. For the cloud scene simulated in this study, seven DWR observations were included with a vertical spacing of $150-200 \mathrm{~m}$. Linking the observations $\mathbf{y}$ with the state vector $\mathbf{x}$, the radiative transfer model PAMTRA (Mech et al. 2020) is used as forward function $F(\mathbf{x})$.

To find a consistent solution, the prior profile $\mathbf{x}_{a}$ should represent the natural atmospheric conditions around Barbados. 

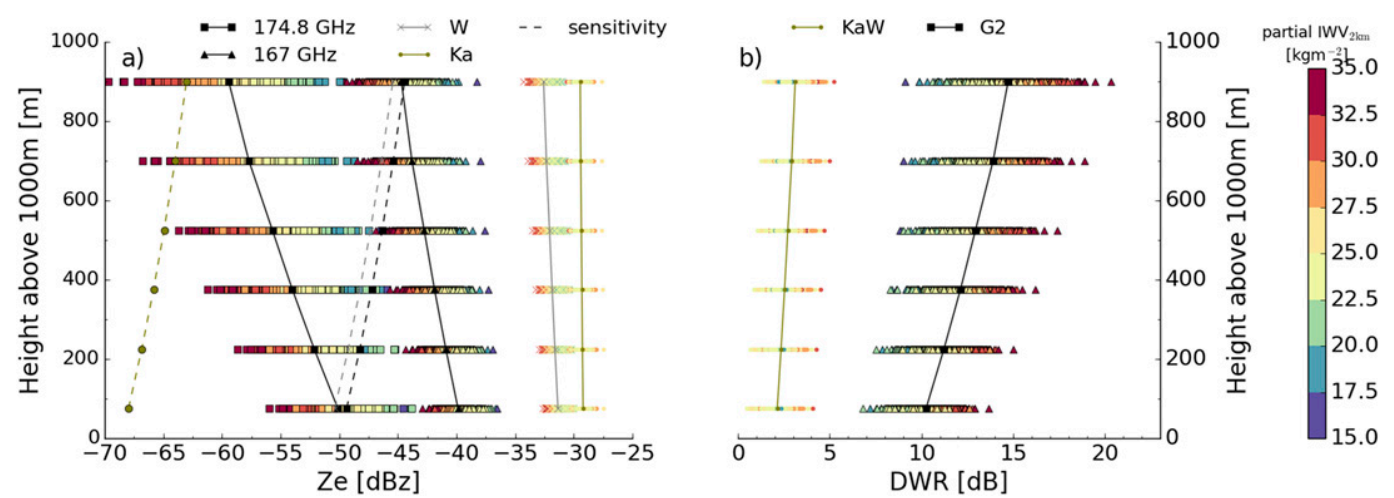

FIG. 2. Simulated (a) radar reflectivity $Z_{e}$ at $35.5 \mathrm{GHz}$ (dots), $94 \mathrm{GHz}(\times), 167.0 \mathrm{GHz}$ (triangles), and $174.8 \mathrm{GHz}$ (squares) and (b) resulting DWR for KaW (dots, olive) and G2 (squares, black) frequency combination. $Z_{e}$ and DWR are plotted as function of height above an assumed cloud base of $1000 \mathrm{~m}$, and color coded by water vapor amount below $2000 \mathrm{~m}$. The mean $Z_{e}$ and DWR are shown (solid line), as well as the respective radar sensitivity thresholds given in Table 1 (dashed). Simulations were based on 633 radiosonde profiles from 2018 with cloud-base and cloud-top heights assumed at 1000 and $2000 \mathrm{~m}$, respectively. A cloud LWP of $50 \mathrm{~g} \mathrm{~m}^{-2}$ with constant LWC of $0.05 \mathrm{~g} \mathrm{~m}^{-3}$ was assumed.

Therefore, we built an absolute humidity profile prior climatology from all operationally available radiosonde ascents launched at 0000 or 1200 UTC at Grantley Adams International Airport located $30 \mathrm{~km}$ southwest of $\mathrm{BCO}$ from 2002 until 2017. We control the sounding quality by excluding sondes with incomplete temperature, pressure, or relative humidity measurements, as well as those not reaching $20 \mathrm{~km}$ height, and, hence, consider 4620 sondes. The prior state and covariance are derived for the dry and the wet season, respectively, as described in Stevens et al. (2017). For the dry season from December through May, 1862 sondes are available, and 2758 sondes for the wet season stretching from June through November. As in the approach presented by Turner and Löhnert (2014), the prior LWP is assumed to be $0 \mathrm{~g} \mathrm{~m}^{-2}$ with a variance of $50 \mathrm{~g} \mathrm{~m}^{-2}$, excluding correlations with the water vapor states. Here, the prior state is also used as first guess.

We assume that the measurement errors are uncorrelated, and use a TB uncertainty of $\Delta \mathrm{TB}=0.4 \mathrm{~K}$ in each of the microwave channels, and a $Z_{e}$ uncertainty of $\Delta Z_{e}=0.4 \mathrm{~dB}$ for all radar frequencies (see section 2a). According to error propagation, the uncorrelated $Z_{e}$ errors lead to a DWR uncertainty of $0.56 \mathrm{~dB}$. The $2 \mathrm{~m}$ humidity measurement $\rho_{2 \mathrm{~m}}$ is assumed to be affected by a $10 \%$ relative error. For simplicity reasons, we neglect possible errors due to forward model assumptions like the DSD parameters, the effective radius or the LWC profile shape, but give estimates of the sensitivity of our results to these parameters, as well as the assumed measurement uncertainties $\left(\mathbf{S}_{e}\right)$ and prior covariances $\left(\mathbf{S}_{a}\right)$ in section $5 b$.

In the following analyses, we will use three criteria to estimate the quality of the retrieved profile $\mathbf{x}_{\mathrm{op}}$, and to quantify the synergistic benefit: the DFS; the a posteriori error of each state, given by the diagonal entries of the $\mathbf{S}_{\mathrm{op}}$ matrix; and the comparison of the retrieved profile to the original radiosonde absolute humidity profile used to generate the synthetic observations.

\section{Synthetic observations}

Synthetic observations of MWR K-band TBs and radar reflectivities $Z_{e}$ for $\mathrm{Ka}, \mathrm{W}$, and $\mathrm{G} 2$ were generated by forward simulating 633 quality-controlled radiosonde profiles from 2018, using the method described in section 2a.

All simulated radar reflectivities as well as the resulting DWRs are presented as function of height above cloud base in Fig. 2. Shown are the attenuated reflectivities, that is the twoway attenuation of the signal due to liquid and water vapor attenuation along the path subtracted from the unattenuated simulated reflectivity. The DWR were calculated for the KaW and $\mathrm{G} 2$ combination by subtracting the respective reflectivities from another. A random measurement error was added to the simulated $Z_{e}$ as described in section 2a.

The reflectivity in each frequency decreases with height due to cumulating water vapor and liquid attenuation along the ray path. The attenuation strength depends on the frequency, and is strongest nearest the water vapor absorption line at 183.31 GHz. Thus, between 1000 and $2000 \mathrm{~m}, \mathrm{Ka}$ - and W-band reflectivities only decrease by less than $1 \mathrm{~dB}$ due to continuum absorption, whereas the G-band reflectivities, located on the wing of the absorption line, decrease on average by 4.8 and $9.3 \mathrm{~dB}$ in 167 and $174.8 \mathrm{GHz}$, respectively. Lower water vapor amounts below $2000 \mathrm{~m}$, thus weaker water vapor attenuation, lead to higher reflectivities per range bin, an effect that is particularly pronounced in the water vapor sensitive G-band frequencies.

Not only does the attenuation strength change depending on the frequency, but so does the differential attenuation between $\mathrm{KaW}$ and the $\mathrm{G} 2$ frequencies. As attenuation increases strongly along the wing of the $183.31 \mathrm{GHz}$ water vapor line, the resulting attenuation gradient is higher compared to the respective gradient of the continuum absorption between Ka and W. Therefore, the DWR G2 signal is higher than the KaW signal, and also increases stronger with height, as attenuation cumulates along the ray path. Between 1000 and $2000 \mathrm{~m}$, 

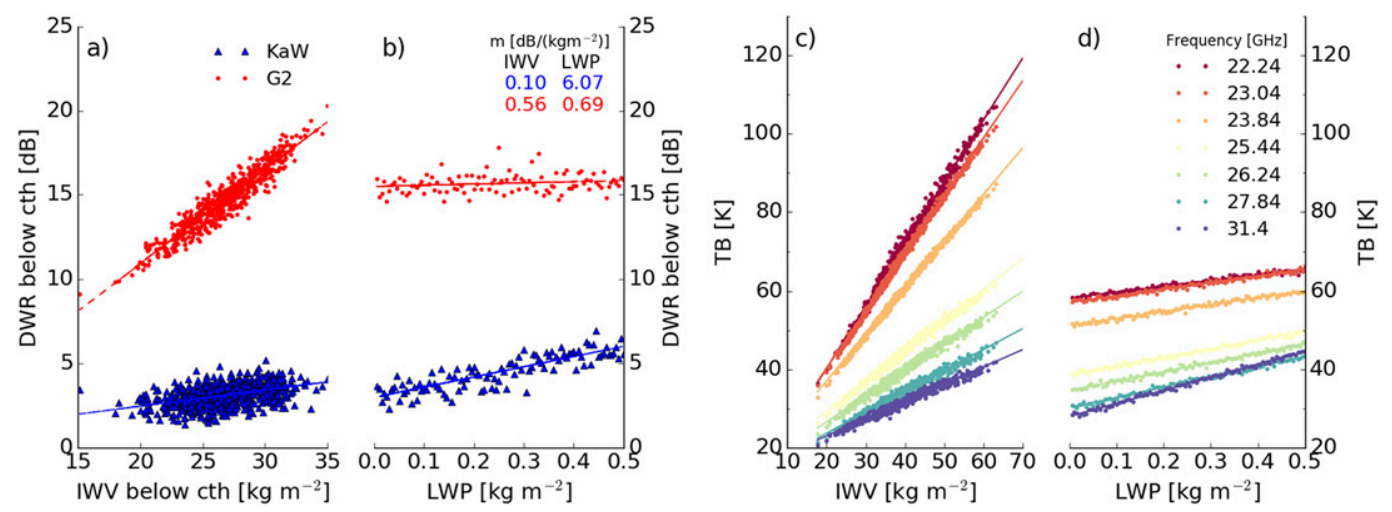

FIG. 3. DWR in radar range gate right below cloud top for KaW (blue) and G2 (red) frequency combination, and simulated MWR K-band TBs (frequency color coded) as function of (a) partial IWV below cloud top (2000 m), (c) total IWV, and (b),(d) LWP. Depicted DWRs and TBs are (a),(c) the same synthetic observations shown in Fig. 2 for a LWP of $50 \mathrm{~g} \mathrm{~m}^{-2}$, and (b),(d) for one radiosonde profile with partial IWV below cloud top of $27.6 \mathrm{~kg} \mathrm{~m}^{-2}$ (total IWV of $32.6 \mathrm{~kg} \mathrm{~m}^{-2}$ ) and varying LWP. In all simulations, cloud-base and cloud-top heights were located at 1000 and $2000 \mathrm{~m}$, respectively, and LWC was constant with $0.05 \mathrm{~g} \mathrm{~m}^{-3}$. The DWR increase per water vapor and liquid amount is given by the slope of the respective linear fit function.

the DWR increases on average by $1.0 \mathrm{~dB}(\mathrm{KaW})$ and $6.6 \mathrm{~dB}$ (G2). Lower water vapor amounts reduce the vertical dynamical range of the DWR signal.

The influences of water vapor and liquid water to the DWR signals are illustrated in Fig. 3a. Shown for the synthetic cloud scenario used in this study, the KaW and G2 DWRs depend linearly on the water vapor path between radar and targets. For both frequency combinations, the Pearson correlation coefficient is nearly one. An increase of partial IWV of $1 \mathrm{~kg} \mathrm{~m}^{-2}$ leads to an increase of DWR at cloud top of $0.1 \mathrm{~dB}(0.6 \mathrm{~dB})$ for $\mathrm{KaW}(\mathrm{G} 2)$, as denoted by the slope $m$ of a linear fit function. Figure $3 \mathrm{~b}$ shows that the DWR KaW at cloud top increases with cloud LWP, leading to a gain of signal of $6.1 \mathrm{~dB}$ $\left(1 \mathrm{~kg} \mathrm{~m}^{-2}\right)^{-1}$ added liquid, whereas the G2 DWR only increases by $0.7 \mathrm{~dB}\left(\mathrm{~kg} \mathrm{~m}^{-2}\right)^{-1}$. The MWR TBs vary as expected: whereas the TB in the $22.24 \mathrm{GHz}$ channel increases

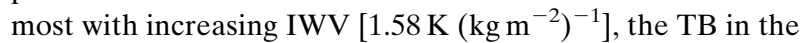
window channel at $31.4 \mathrm{GHz}$ is most sensitive to changes in LWP [33.3 $\left.\mathrm{K}\left(\mathrm{kg} \mathrm{m}^{-2}\right)^{-1}\right]$.

The sensitivities of KaW and G2 DWR, as well as the MWR TBs, give an initial impression about the synergy potential of these observations for the retrieval. Whereas the DWR G2 signal shows an enhanced sensitivity to varying partial IWV along the beam path, the differential liquid attenuation contribution to DWR G2 is small. In case of DWR KaW, however, differential liquid attenuation contributions are of similar magnitudes than the signal sensitivity due to changing water vapor conditions. The MWR TBs are sensitive to both water vapor and liquid water.

Even though these results suggest that the G2 synergy would be particularly beneficial for water vapor profiling retrievals, sensitivity thresholds of current G-band technology might prohibit the penetration of the entire cloud layer. With the current potential of the VIPR system, a single-pulse sensitivity threshold of $-40 \mathrm{~dB} z$ is reached at $1 \mathrm{~km}$ with a $15 \mathrm{~m}$ range resolution and $1 \mathrm{~ms}$ integration time. Given these technical constraints, the assumed cloud top at $2000 \mathrm{~m}$ (see Fig. 2) would not be detected at 167 or $174.8 \mathrm{GHz}$, and cloud base would be undetectable with the $174.8 \mathrm{GHz}$ channel for all simulated cases. Decreasing the vertical resolution to $150 \mathrm{~m}$ or applying noncoherent signal processing could improve the sensitivity to $-50 \mathrm{~dB} z$ at $1 \mathrm{~km}$ (see Table 1 ), which would lead to a detection of $33.3 \%$ of the simulated cloud bases at $174.8 \mathrm{GHz}$. Assuming a detection threshold of $-60 \mathrm{~dB} z$ for future radar systems with increased transmitter power would allow detection of all simulated cloud bases. In $60.0 \%$ of all simulated cases, the modeled cloud would be profiled up to $1500 \mathrm{~m}$.

Therefore, in the following synergy analysis, the retrieval grid spacing was selected such that the retrieval resolution varies between 150 and $200 \mathrm{~m}$ in the cloud layer. As G-band technology is only at the early stage of development and sensitivities might change in future systems, no sensitivity threshold was applied to the synthetic radar observations in the synergy analyses, and full cloud profiling potential was assumed. The impact of different sensitivity thresholds and, thus, different cloud penetration depths, on the retrieval is analyzed in section $5 b$ by reducing the number of DWRs in the observation vector.

\section{Case study}

The selected case study is based on a radiosonde launched at BCO at 1406 UTC (1006 local time)19 February 2019. On that day, the atmosphere showed typical features for a trade winddriven scene: a strong temperature inversion layer located between 2350 and $2600 \mathrm{~m}$ with a temperature increase of $4 \mathrm{~K}$; a strong absolute humidity gradient of $8.5-0.2 \mathrm{~g} \mathrm{~m}^{-3}$, corresponding to $97 \%$ and $0 \%$ relative humidity change within the inversion layer; the lifting condensation level (LCL) located at $660 \mathrm{~m}$; and a shallow cloud layer located below the inversion layer with cloud base around $1000 \mathrm{~m}$ and cloud top around $2300 \mathrm{~m}$. The sonde measured a column IWV of $32.6 \mathrm{~kg} \mathrm{~m}^{-2}$. Using the simulation setup described in section 2 with cloud-top 

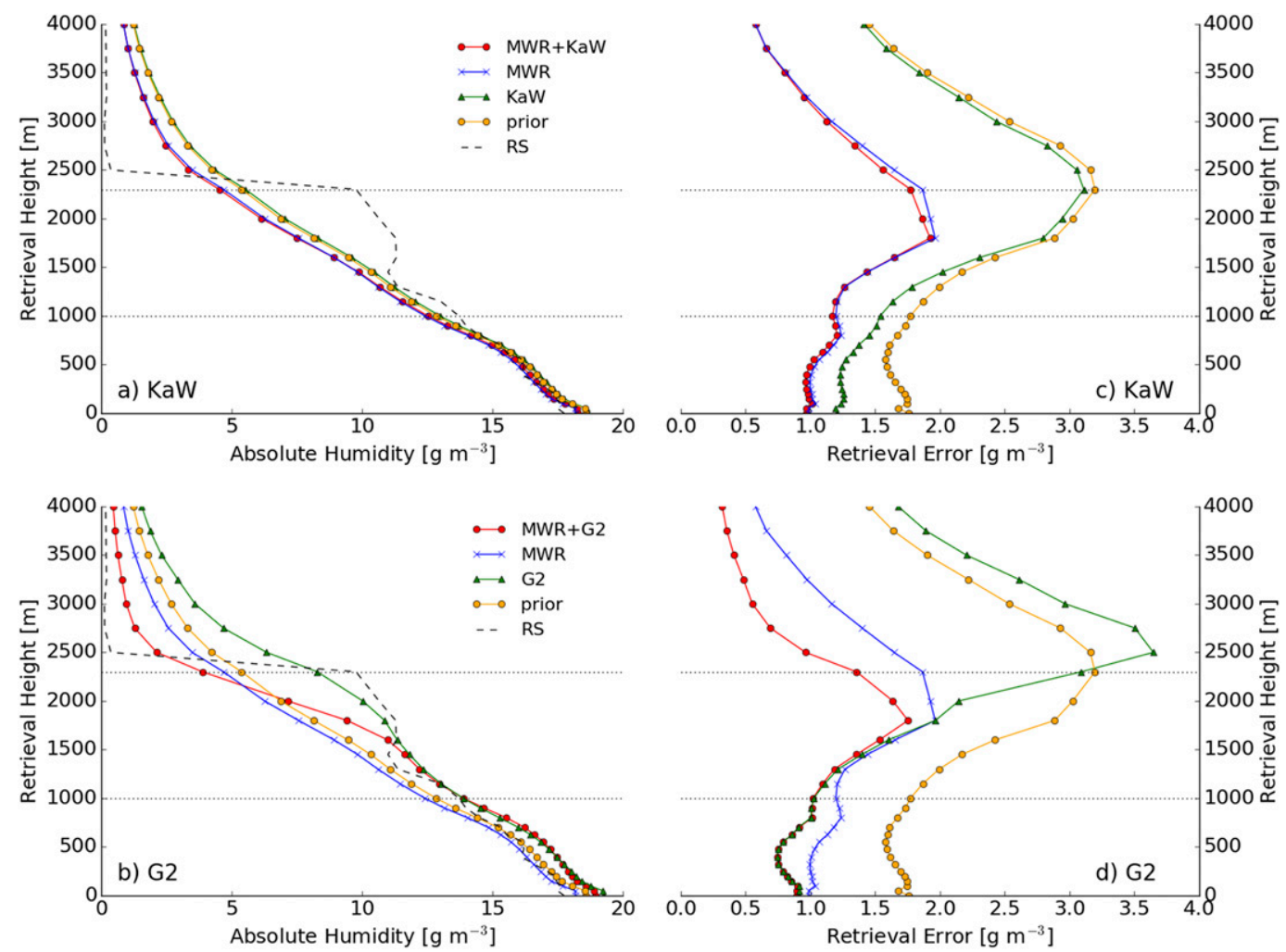

FIG. 4. Case study results for (a),(b) retrieved absolute humidity profile and (c),(d) a posteriori retrieval error. Different retrieval setups were used: MWR-only (blue), radar-only (green), and MWR + radar (red) for (a),(c) $\mathrm{KaW}$ radar frequencies and (b),(d) G2 radar frequencies. Case study radiosonde profile (black dashed) and prior profile and error (orange) are shown for comparison. Cloud-base and cloud-top heights are located at 1000 and $2300 \mathrm{~m}$ (black dotted lines), respectively.

height located at $2300 \mathrm{~m}$, the simulated MWR TBs decrease from $59.2 \mathrm{~K}(22.24 \mathrm{GHz})$ to $30.2 \mathrm{~K}(31.4 \mathrm{GHz})$. At cloud base, $Z_{e}$ reaches $-30.5 \mathrm{~dB} z(-32.7 \mathrm{~dB} z)$ for the $\mathrm{Ka}(\mathrm{W})$ frequency, and $-40.6 \mathrm{~dB} z(-51.5 \mathrm{~dB} z)$ at $167 \mathrm{GHz}(174.8 \mathrm{GHz})$, respectively. The observed $2 \mathrm{~m}$ humidity $\left(\rho_{2 \mathrm{~m}}\right)$ was $18.9 \mathrm{~g} \mathrm{~m}^{-3}$.

Figures $4 \mathrm{a}$ and $4 \mathrm{~b}$ show the radiosonde absolute humidity profile, as well as the retrieval results using MWR-only, the synergistic MWR + radar approach, and radar-only for both frequency combinations. All setups converge and pass the $\chi^{2}$ test.

The retrieved profile using the MWR-only setup agrees well with the original radiosounding below the inversion layer. Within and above the inversion layer, the retrieval does not resolve the strong humidity gradient, but smooths the profile. The difference between retrieved and radiosonde absolute humidity at cloud top is $5.1 \mathrm{~g} \mathrm{~m}^{-3}$ in case of the MWR-only retrieval setup, with the retrieval underestimating the radiosonde water vapor amount below cloud top. Above the inversion layer, the retrieval overestimates the radiosonde measurements by about the same amount. The retrieved IWV of $31.7 \mathrm{~kg} \mathrm{~m}^{-2}$ matches the radiosonde IWV by a difference of $1 \mathrm{~kg} \mathrm{~m}^{-2}$ within the associated uncertainty range. This case nicely illustrates the restrictions of profiling retrievals based on pure MWR observations: whereas the IWV amount of the retrieved profile matches the observed state of the atmosphere, the retrieved profile does not represent the vertical distribution of water vapor correctly particularly around the inversion layer.

When combining the MWR and radar observations using the synergistic KaW setup (see Fig. 4a), we expect the discrepancy between radiosonde and retrieval profile to decrease within the cloud layer due to the information added by the radar. At cloud base, the difference between radiosonde and retrieved profile reduces to $1.2 \mathrm{~g} \mathrm{~m}^{-3}$. The profiles of both setups agree with the radiosonde profile within the range of uncertainty. Throughout the cloud layer, the addition of $\mathrm{KaW}$ does not lead to an improved agreement between retrieved and radiosonde profile. When adding the DAR G2 observations to the retrieval as shown in Fig. 4b, however, the retrieved profile agrees with the radiosonde profile within the retrieval uncertainties, particularly within the lower part of the cloud. In the upper part of the cloud, the humidity gradient is not fully captured, but better represented than in the MWR-only setup. The G2-only retrieval performs well within the cloud layer, but cannot capture the profile above the cloud.

As shown in Fig. 4c, the a posteriori error of the retrieved MWR-only profile increases from 1.0 and 1.2 to $1.9 \mathrm{~g} \mathrm{~m}^{-3}$ from ground level to cloud base and top, respectively. Adding KaW observations to the retrieval decreases the error at cloud top 
TABLE 2. Case study DFS for different retrieval setups: synergistic approach with MWR and dual-frequency radar observations, MWR-only configuration, and dual-frequency-radar-only. Dualfrequency radar observations were evaluated for $\mathrm{KaW}$ and $\mathrm{G} 2$ frequency pairs. The synergistic and DAR-G2 only retrieval were also run with a reduced observation vector setup only taking into account DWR measurements if both simulated radar reflectivities were above a sensitivity limit of $-60 \mathrm{~dB} z$ at $1000 \mathrm{~m}$. Given are the total DFS, the DFS for the LWP state, the sum of DFS for all water vapor (WV) states, and the partial water vapor DFS for below, within, and above the cloud layer.

\begin{tabular}{|c|c|c|c|c|c|c|c|}
\hline \multirow[b]{2}{*}{ DFS } & \multicolumn{3}{|c|}{$\begin{array}{l}\text { Synergistic } \\
\text { MWR and }\end{array}$} & \multirow[b]{2}{*}{ MWR } & \multicolumn{3}{|c|}{$\begin{array}{l}\text { Dual- } \\
\text { frequency radar }\end{array}$} \\
\hline & $\mathrm{KaW}$ & G2 & $\mathrm{G} 2_{-60}$ & & $\mathrm{KaW}$ & $\mathrm{G} 2$ & $\mathrm{G} 2_{-60}$ \\
\hline Total & 3.20 & 4.28 & 3.67 & 3.06 & 1.52 & 2.34 & 1.21 \\
\hline LWP & 0.99 & 1.00 & 0.99 & 0.99 & 0.88 & 0.01 & 0.01 \\
\hline WV & 2.21 & 3.28 & 2.67 & 2.07 & 0.64 & 2.33 & 1.21 \\
\hline $\mathrm{WV}_{\text {below }}$ & 0.57 & 0.89 & 0.87 & 0.52 & 0.57 & 0.89 & 0.90 \\
\hline $\mathrm{WV}_{\text {in }}$ & 0.44 & 1.17 & 0.83 & 0.40 & 0.07 & 1.44 & 0.31 \\
\hline $\mathrm{WV}_{\text {above }}$ & 1.18 & 1.23 & 0.97 & 1.15 & 0.0 & 0.0 & 0.0 \\
\hline
\end{tabular}

slightly, by $0.1 \mathrm{~g} \mathrm{~m}^{-3}$. As shown in Fig. $4 \mathrm{~d}$, the error of the synergistic MWR + G2 retrieval is similar to the error of the DAR G2-only approach below cloud base, reducing the error to $0.7 \mathrm{~g} \mathrm{~m}^{-3}$ at $400 \mathrm{~m}$. Toward cloud top, the error of the DAR G2-only setup increases, while the synergistic error further decreases compared to the MWR-only retrieval setup. The synergistic benefit of combining MWR and DAR G2 is pronounced particularly in these layers with an improvement of error compared to the MWR-only setup of up to $1.0 \mathrm{~g} \mathrm{~m}^{-3}$ at $3000 \mathrm{~m}$.

The information gain through the instrument synergy, and the vertical distribution of the available information can be analyzed through the DFS summarized in Table 2. The MWRonly setup reaches $3.06 \mathrm{DFS}$ in total. When adding $\mathrm{KaW}$ to MWR, the total DFS do not increase considerably, but the addition of DAR G2 to the MWR increases the available DFS to 4.28. In both synergistic combinations as well as the MWRonly setup, one piece of information is used for LWP. The $\mathrm{KaW}$-only configuration contains reduced information about the LWP, whereas the G2-only does not give any information about the LWP.

Table 2 and Fig. 5 illustrate the vertical partitioning of the information content in respect to the cloud layer, plotted relative to the MWR-only setup. Below the cloud layer, the synergistic retrieval information in both setups originates from the radar observations, with the DAR G2 combination providing a higher information content compared to the KaW frequencies ( 0.89 vs $0.57 \mathrm{DFS}$, respectively). In the cloud layer, the synergy of MWR + G2 increases the available information by 0.77 DFS compared to the MWR-only setup, but shows a slightly reduced information content compared to the G2-only approach. The synergistic benefit of the joint MWR + G2 retrieval is pronounced above cloud, where the information content is further enhanced compared to the MWR-only approach. Increasing information content correlates with a

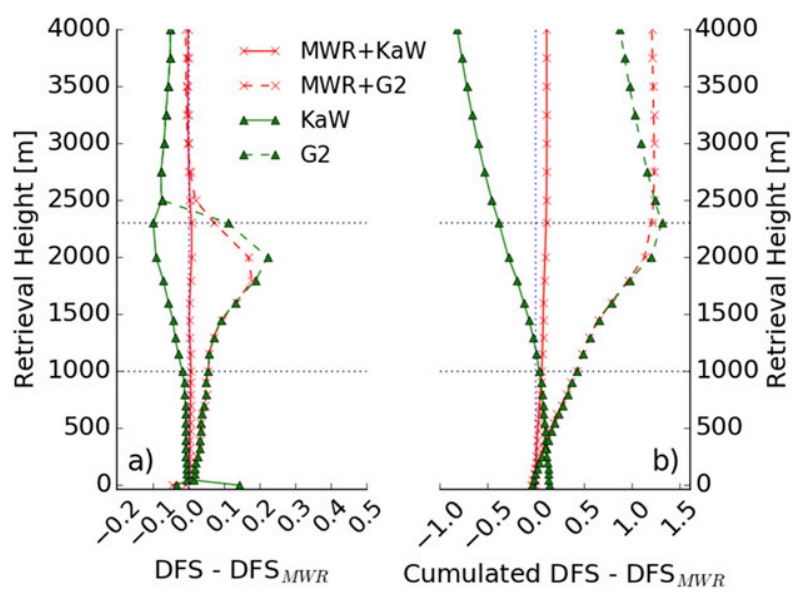

FIG. 5. Relative DFS to MWR-only retrieval of the case study retrieved profiles (a) per retrieved state and (b) vertically cumulated. Shown are the synergistic retrieval setups (red) and the radar-only setups (green) for both frequency pairs KaW (solid) and G2 (dashed). Note that the cumulative DFS in (b) include the DFS for $\rho_{2 \mathrm{~m}}$, and the DFS up to $4 \mathrm{~km}$ height.

reduced retrieval error for the respective states (cf. Figs. 4c,d). In case the G-band radar system's reflectivity sensitivity threshold were $-50 \mathrm{~dB} z$ at $1000 \mathrm{~m}$, cloud base at $1000 \mathrm{~m}$ would not be detected, and the synergistic approach would not enhance the information content compared to the MWR-only approach. If a sensitivity threshold of $-60 \mathrm{~dB} z$ at $1000 \mathrm{~m}$ were assumed, however, cloud base would be detectable, but not the full cloud would be profiled. The synergistic observation vector, thus, would comprise TBs, $\rho_{2 \mathrm{~m}}$, and the DWR measurements at three height levels from cloud base up to $1450 \mathrm{~m}$. Using this reduced setup, the total synergistic information content would be enhanced compared to the MWR-only approach, but the synergistic benefit for the water vapor states above the cloud layer would be reduced compared to the full-cloud profiling application (see Table 2). Full-cloud profiling in this particular scene would require a sensitivity threshold in the $\mathrm{G} 2$ frequencies of better than $-70 \mathrm{~dB} z$ at $1000 \mathrm{~m}$, given the assumptions made in the forward modeling (see section 2a).

In case of the MWR + KaW synergy, only little information is provided by the radar observations, as can be explained by the stronger differential liquid attenuation component in the DWR KaW signal, and the resulting lower signal-to-noise ratio (SNR) with respect to changing water vapor conditions. This dependency, however, is beneficial when looking at the LWP DFS: in case of KaW-only, 0.88 of the total 1.52 DFS are attributed to LWP, whereas DAR G2 contains no information about the LWP.

\section{Retrieval statistics and sensitivity}

\section{a. Statistics under varying water vapor conditions}

Expanding the case study analysis to a statistics of varying water vapor conditions, we evaluate all observations presented in section 3 based on 633 atmospheric profiles and forward simulated with the method described in section $2 \mathrm{a}$. The vertical 


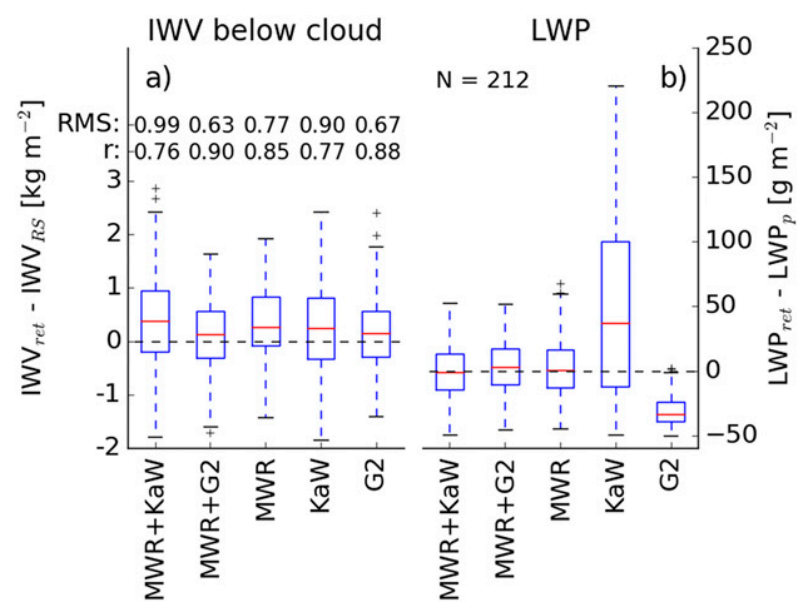

FIG. 6. Difference between (a) retrieved partial IWV to RS partial IWV and (b) retrieved LWP to assumed LWP for all different retrieval setups. Shown are median (red), 10th, 25th, 75th, and 90th percentiles (blue) and outliers (black) of MWR-only, radar-only, and synergistic setups analyzed for KaW and G2 DAR pairs. The top and bottom numbers in (a) refer to the Pearson correlation coefficient $r$ and the RMS error, respectively. All physical converging cases of quality-controlled radiosonde profiles from 2018 were analyzed, resulting in 212 analyzed cases that converged in all different retrieval configurations.

absolute humidity profiles together with the LWP are retrieved from the synthetic observations with varying observation vector configuration: MWR-only, radar-only, and the synergistic setup. Even though the assumption of a cloud between 1000 and $2000 \mathrm{~m}$ might not be represented by each of the atmospheric moisture conditions, we assume that the synergistic benefits regarding the information content and retrieval error will, however, qualitatively not change.

Both the synergistic and MWR-only retrieval setup reach convergence rates of nearly $100 \%$. The retrieval based on pure dual-frequency radar observations shows lower convergence rates due to missing radar observations above cloud layer: there, all information content is determined by the prior climatology. Therefore, in the following, we analyze a reduced subsample of 212 cases that converge and pass the $\chi^{2}$ test in all different retrieval configurations.

All retrieval setups cover the expected spread of IWV below cloud base given by the radiosondes as shown in Fig. 6a. The median values agree with the RS within $0.5 \mathrm{~kg} \mathrm{~m}^{-2}$. The setups using radar-only observations show application potential for retrieving the partial IWV amount below cloud base. The setups including the G2 observations show an increasing correlation $r$ to 0.9 , and a decreasing RMS compared to the MWR-only retrieval runs. In case of the MWR $+\mathrm{KaW}$ combination, the opposite is true with the RMS increasing to $1 \mathrm{~kg} \mathrm{~m}^{-2}$. As shown in Fig. 6b, the medians of both synergistic retrieved LWPs agree with the assumed LWP of $50 \mathrm{~g} \mathrm{~m}^{-2}$ due to the information included by the MWR. $50 \%$ of the results lie within the range of $\pm 20 \mathrm{~g} \mathrm{~m}^{-2}$. However, the LWP retrieved from radar-only observations disagrees significantly with the assumed LWP of $50 \mathrm{~g} \mathrm{~m}^{-2}$. KaW-only overestimates the LWP,

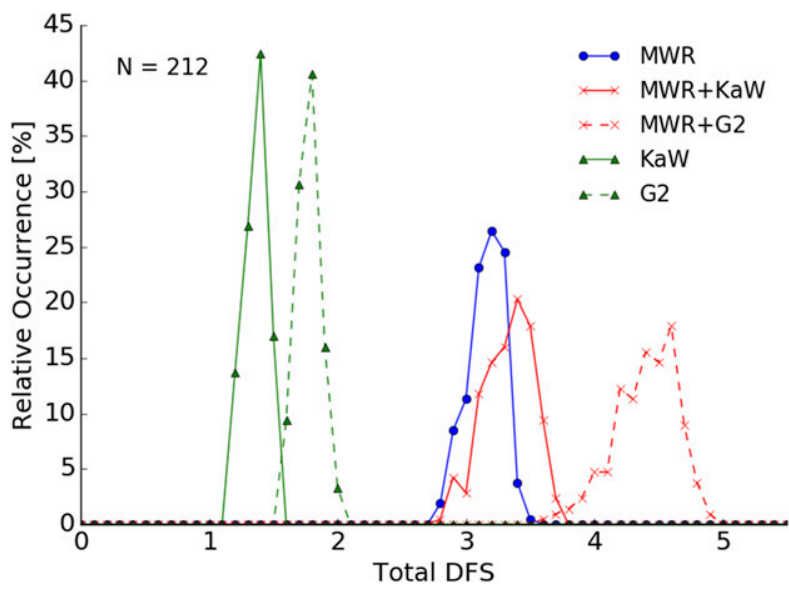

FIG. 7. Frequency of occurrence of total DFS, including DFS for LWP and all water vapor states. All 212 cases analyzed in Fig. 6 were considered using the MWR-only (blue), dual-frequency radar-only (green), and the synergistic retrieval setup (red); dual-frequency radar observations were evaluated for the KaW frequencies (solid), and DAR G2-frequencies (dashed).

showing a large spread of the retrieved values of about $100 \mathrm{~g} \mathrm{~m}^{-2}$; DAR G2 underestimates the LWP significantly, and the spread of the data is low. This discrepancy can be explained by the different sensitivity of the DWR signal to differential liquid water and water vapor attenuation (see Fig. 2). In case of $\mathrm{KaW}$, the signal is similarly affected by both liquid water and water vapor attenuation: the retrieval overcompensates the lack of variation in DWR signal under changing water vapor conditions by increasing the LWP state in order to find a converging solution. In contrast, the sensitivity of DWR G2 to liquid water is smaller, and the LWP result is driven by the prior state.

The distribution of total available DFS is shown in Fig. 7 for all retrieval setups. The MWR-only retrieval contains on average 3.2 DFS. Using the synergistic approach of combining MWR and KaW (DAR G2) observations, the total DFS increase on average by $5.3 \%(38.7 \%)$ to $3.4(4.5)$. In case of using the radar-only observations, the total DFS using the DAR G2 frequencies are on average higher $(\mathrm{DFS}=1.8$ ) than the DFS using KaW (DFS = 1.4). In the synergistic setups, larger water vapor contents below cloud top generally lead to higher DFS.

Figure 8 and Table 3 provide information about the vertical distribution of the information content available to the different retrieval configurations. Below and within the cloud layer, the information content of the synergistic MWR $+\mathrm{G} 2$ retrieval originates from the DAR G2 observations, as the DAR G2 and the synergistic setup both reach 1.8 DFS at $2000 \mathrm{~m}$. Above cloud top, the synergy increases the information content by 0.2 DFS compared to the MWR-only setup. In case of $\mathrm{KaW}$, this synergy effect is not pronounced due to the DWR $\mathrm{KaW}$ signal attenuation ambiguities (see section 3). However, this sensitivity to liquid attenuation leads to an information gain for the LWP state: in case of KaW-only to about 0.9 DFS, whereas DAR G2 contains no information about the LWP. In both synergistic and the MWR-only retrievals, the MWR provides 1 DFS for the LWP. 


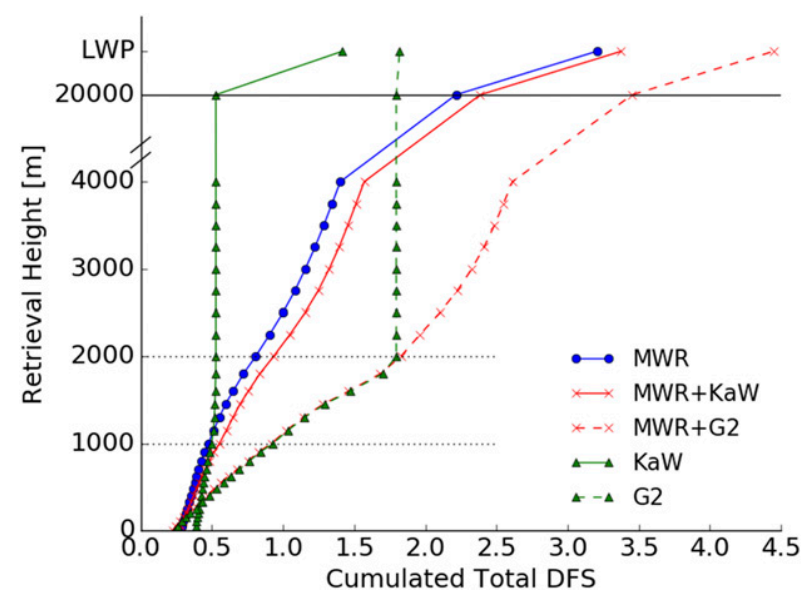

FIG. 8. Mean DFS, vertically cumulated and depicted per retrieval state. Experiment setup, colors, and line style as in Fig. 6. Note that states between 4000 and $20000 \mathrm{~m}$ are not resolved for figure clarity, but are considered in the calculation.

Corresponding to the areas of increased information content, the retrieval error is reduced particularly above and in the upper cloud layer when combining MWR with DAR G2 as shown in Fig. 9. This synergistic effect is most pronounced between cloud top up and $3500 \mathrm{~m}$, resulting in an error decrease of up to $0.2 \mathrm{~g} \mathrm{~m}^{-3}$ compared to the MWR-only retrieval. Below and in the lowest cloud layers, the MWR + G2 error is similar to the G2-only retrieval error, leading to a reduction compared to the MWR-only approach of $28 \%$ from 1.4 to $1.0 \mathrm{~g} \mathrm{~m}^{-3}$. Combining KaW and MWR observations leads to a small error decrease around cloud base of less than $5 \%$, but not to a significant improvement in other areas.

Even though the increase of DFS and the decrease of error is small in case of a synergy of MWR and KaW, a combination of the instruments adds valuable information to the humidity profile retrieval, as passive observations alone cannot successfully partition the retrieved water vapor profile in sub-, in-, and above-cloud layers. Additionally, KaW can add information about LWP and LWC as shown by Hogan et al. (2005). As opposed to KaW, DAR $\mathrm{G} 2$ is almost insensitive to liquid water, and contains information

TABLE 3. Mean DFS for 212 cases converging in all varying retrieval configurations using MWR and KaW or DAR G2 observations. Given are the total DFS, the LWP DFS, the sum of DFS for all WV states, and the partial water vapor DFS for below, within, and above the cloud layer.

\begin{tabular}{|c|c|c|c|c|c|}
\hline \multirow[b]{2}{*}{ DFS } & \multicolumn{2}{|c|}{ MWR and } & \multirow[b]{2}{*}{ MWR } & \multicolumn{2}{|c|}{$\begin{array}{c}\text { Dual- } \\
\text { frequency radar } \\
\end{array}$} \\
\hline & $\mathrm{KaW}$ & G2 & & $\mathrm{KaW}$ & G2 \\
\hline Total & 3.38 & 4.45 & 3.21 & 1.42 & 1.82 \\
\hline LWP & 0.99 & 0.99 & 0.99 & 0.88 & 0.02 \\
\hline WV & 2.39 & 3.45 & 2.21 & 0.53 & 1.80 \\
\hline $\mathrm{WV}_{\text {below }}$ & 0.51 & 0.83 & 0.45 & 0.48 & 0.84 \\
\hline $\mathrm{WV}_{\text {in }}$ & 0.42 & 1.00 & 0.36 & 0.04 & 0.96 \\
\hline $\mathrm{WV}_{\text {above }}$ & 1.45 & 1.63 & 1.41 & 0.0 & 0.0 \\
\hline
\end{tabular}

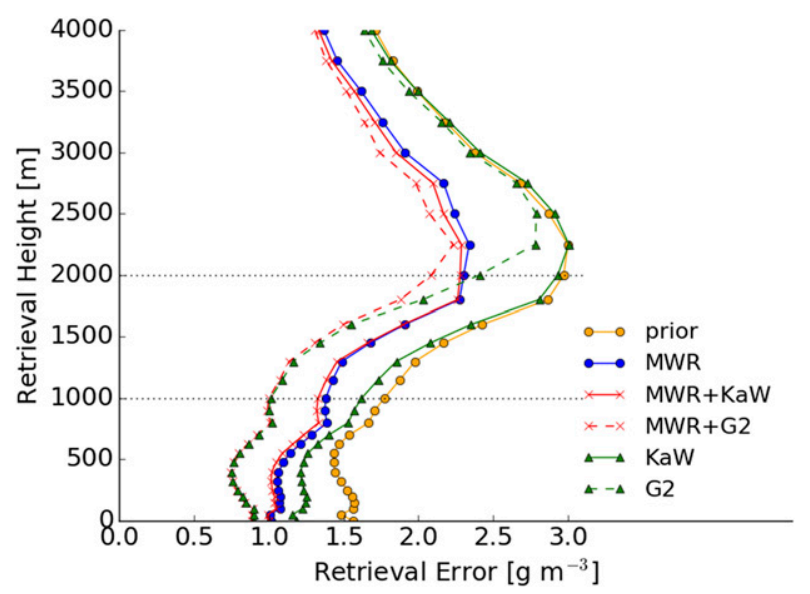

FIG. 9. Mean a posteriori retrieval error of retrieved absolute humidity per retrieval grid step, shown here up to $4000 \mathrm{~m}$. Experiment setup, colors, and line styles are as in Fig. 6; prior uncertainty shown in orange.

about the water vapor distribution below and throughout the cloud layer. Therefore, the MWR provides the information about LWP in the synergistic MWR + G2 setup. Compared to the MWR-only approach, the water vapor information content is increased above the cloud layer due to the instrument synergy.

\section{b. Synergistic retrieval sensitivity to forward model, observation errors, and prior}

After analyzing the retrieval error and information content for varying water vapor conditions, we now investigate the synergistic MWR + G2 retrieval sensitivity to changing forward model assumptions, observation errors, prior covariances, and radar detection thresholds.

The error associated with the forward model assumptions on LWC profile shape, effective radius, and DSD can be estimated following Rodgers (2000) if the parameter errors are uncorrelated. Therefore, we independently compare the observations resulting from the standard setup as described in section $2 \mathrm{a}$ to simulations with an adiabatic-like linearly increasing LWC profile; an increased effective radius $r_{\text {eff }}$ of $15 \mu \mathrm{m}$; and a decreased DSD shape parameter $\sigma_{\mathrm{DSD}}$ of 0.2 . The LWP of $50 \mathrm{~g} \mathrm{~m}^{-2}$ is maintained in all simulations. Based on the case study profile presented in section 4, we also evaluate the retrieval errors induced by the change of each parameter in the forward function when retrieving from the standard simulated observations.

We find that varying the LWC profile shape produces variabilities in the DWRs of less than $1 \%$ in case of the KaW pair and leaves the DWR G2 invariable. These variations induce changes in the total DFS of less than 0.1, and of less than $0.1 \mathrm{~g} \mathrm{~m}^{-3}$ in the retrieval error, respectively. Varying $r_{\text {eff }}$ or $\sigma_{\text {DSD }}$ does not impact the observations or the retrieval error significantly. Thus, we neglect these error contributions under the condition that the non-Rayleigh scattering regime is not reached. Additional uncertainties to the MWR TB introduced by absorption model uncertainties as discussed in Cimini et al. (2018) are assumed to be within the range of the beforementioned analyses performed for doubled TB errors. 


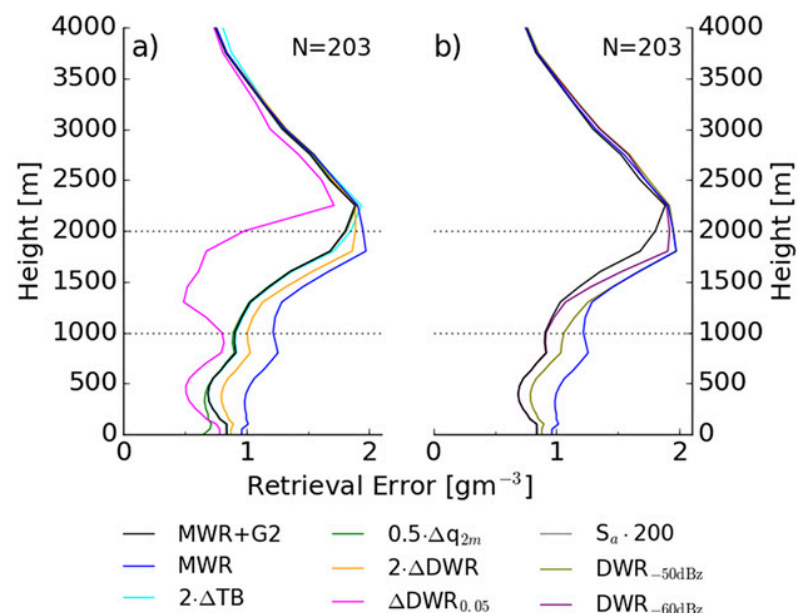

FIG. 10. Mean synergistic a posteriori retrieval error for synergistic MWR + G2 retrieval calculated based on 203 converging cases with different retrieval setups: (a) the standard retrieval with varying $\mathbf{S}_{e}$ and $\mathbf{S}_{a}$ components and (b) a setup with a reduced observation vector setup with MWR TBs, DWR above the respective radar sensitivity threshold, and $\rho_{2 \mathrm{~m}}$. Shown are the mean errors for the standard synergistic retrieval (black), the MWR-only configuration (blue), and (a) doubled TB uncertainty (cyan), halved $\rho_{2 \mathrm{~m}}$ error (green), doubled DWR error (orange), and reduced and coupled DWR error (magenta), as well as inflated prior covariance (gray); (b) a reduced observation vector setup using MWR TBs and DWR calculated for layers with $Z_{e}$ above $-50 \mathrm{~dB} z$ (olive) and above $-60 \mathrm{~dB} z$ (purple).

To quantify the synergistic benefit under varying observational error magnitudes, we repeat the statistical synergistic MWR + G2 analysis while varying the diagonal elements of the $\mathbf{y}$-covariance matrix, as well as the noise of the respective observations accordingly: doubled TB error, doubled DWR error and halved relative $\rho_{2 \mathrm{~m}}$ error. Modeling an optimally intercalibrated dual-frequency radar instrument, we also investigate the impact of adding the same random noise factor to both $Z_{e}$, and reducing the DWR noise to $0.05 \mathrm{~dB}$. Additionally, we test the sensitivity of the MWR + $\mathrm{G} 2$ retrieval to the magnitude of the prior covariance matrix by multiplying all elements of $\mathbf{S}_{a}$ by various factors (here shown for 200) while conserving the correlation between all elements. In all setups, the measurement errors are assumed to be uncorrelated. Figure 10a shows the mean square root of all $\mathbf{S}_{\mathrm{op}}$ diagonal elements for a subsample of 203 cases which reach true convergence in all different retrieval configurations.

Doubling the TB error leads to an increase of the retrieval uncertainty above cloud top by $0.1 \mathrm{~g} \mathrm{~m}^{-3}$. Doubling the DWR error, which would correspond to a lowering of the radar SNR, leads to an increase of error in and under the cloud layer of around $0.1 \mathrm{~g} \mathrm{~m}^{-3}$. Halving the $\rho_{2 \mathrm{~m}}$ uncertainty improves the retrieval performance by $0.1 \mathrm{~g} \mathrm{~m}^{-3}$ in the layers just above ground. The largest impact is seen when the radar system is assumed to be perfectly intercalibrated. Then, the retrieval error decreases particularly within the cloud layer and, right below cloud top, reduces by $1.0 \mathrm{~g} \mathrm{~m}^{-3}$ compared to the original
TABLE 4. Mean DFS for 203 converging cases, calculated for MWR + G2 synergistic setup without sensitivity restrictions, with a radar sensitivity of -50 and $-60 \mathrm{~dB} z$ applied, and the MWR-only retrieval setup.

\begin{tabular}{lcccc}
\hline \hline \multicolumn{1}{c}{ DFS } & MWR & MWR + G2 & $\begin{array}{c}\text { MWR }+\mathrm{G} 2, \\
-60 \mathrm{~dB} z\end{array}$ & $\begin{array}{c}\text { MWR + G2, } \\
-50 \mathrm{~dB} z\end{array}$ \\
\hline Total & 3.09 & 4.16 & 3.94 & 3.50 \\
LWP & 0.99 & 0.99 & 0.99 & 0.99 \\
WV & 2.10 & 3.17 & 2.95 & 2.50 \\
$\mathrm{WV}_{\text {below }}$ & 0.51 & 0.85 & 0.85 & 0.77 \\
$\mathrm{WV}_{\text {in }}$ & 0.39 & 0.90 & 0.72 & 0.46 \\
$\mathrm{WV}_{\text {above }}$ & 1.20 & 1.43 & 1.38 & 1.27 \\
\hline
\end{tabular}

MWR + G2 setup. Simultaneously, the DFS nearly double within the cloud layer (not shown). The retrieval error is insensitive to magnitude changes of the prior covariance matrix as long as the correlations between all elements are conserved. The presented error sensitivity study is particularly important when moving from synthetic to real observations. The DWR uncertainty in particular could be enhanced for real instruments to account for sensor misalignment and nonuniform beam filling effects, as well as due to the vertical dependence of the radar's SNR. Hogan et al. (2005) further describe how to quantify these errors.

As discussed in section 3, current G-band radars might only be able to penetrate the lowest cloud layers. While the analyses before assumed that the entire cloud layer is penetrated independent from radar sensitivity thresholds, the dependence of the MWR + G2 synergy retrieval to partial cloud profiling is now investigated. We therefore run the retrieval with a different observation vector configuration which consists of all TBs, $\rho_{2 \mathrm{~m}}$, and the DWR calculated only for those layers, where the reflectivity in both frequencies lies above the respective sensitivity limit. As the received power is inversely proportional to the square of the range, the respective thresholds were calculated for each cloud layer. A threshold of $-50 \mathrm{~dB} z$ at $1000 \mathrm{~m}$ was selected based on the single-pulse VIPR sensitivity with a range resolution of $150 \mathrm{~m}$, whereas a sensitivity of $-60 \mathrm{dBz}$ is assumed to be achievable with future, more powerful transmitters.

Only $33.3 \%$ of the simulated $174.8 \mathrm{GHz}$ reflectivities at $1000 \mathrm{~m}$ reach a reflectivity of larger than $-50 \mathrm{~dB} z$. In $96 \%$ of these cases, only the lowest cloud layer right above cloud base is detected, and, thus, only one DWR measurement is added to the observation vector. With a sensitivity threshold of $-60 \mathrm{~dB} z$, the lowest cloud layer can be observed for all simulated cases. Toward cloud top, the number of detected cases reduces to $60.0 \%$ at $1500 \mathrm{~m}$, and $7.6 \%$ at cloud top. Thus, the number of DWR in the observation vector varies depending on each specific case. The retrieval error and information content of the same subset of 203 cases were analyzed, and are summarized in Fig. 10b and Table 4. For comparison, the error and information content for the retrieval without detection thresholds are added to the analysis.

When a sensitivity of $-50 \mathrm{~dB} z$ is assumed, the retrieval error of the synergy setup is mainly reduced below and within the lowest cloud layer, as no DWR observations above are available. 
The reduction of error compared to an MWR-only setup is accompanied by a gain of information content for the water vapor profile below the cloud. Compared to the optimal MWR + G2 setup, the slightly reduced information content below cloud leads to an increase of retrieval error of $1.0 \mathrm{~g} \mathrm{~m}^{-3}$. Throughout the cloud layer, the retrieval error blends with the MWR-only error, as no additional observations are available. The synergistic information content gain above the cloud layer is reduced.

When applying a threshold of $-60 \mathrm{~dB} z$, DWR observations are available deeper into the cloud layer. Therefore, the information content is reduced particularly throughout the cloud layer compared to the optimal setup, and the retrieval error increases toward cloud top with decreasing availability of observations. However, the synergistic information gain above the cloud layer is only marginally reduced compared to the optimal setup, leading to an increase of total DFS by 0.9 compared to the MWR-only retrieval (vs 1.1 DFS for the original MWR + G2).

Even though the synergistic benefits are less pronounced when a sensitivity threshold is considered, our results suggest that a synergistic deployment of MWR and DAR G2 would be beneficial even with current technological detection thresholds.

\section{Conclusions and future studies}

Continuous, high-resolution water vapor profile observations in the lower troposphere are essential for quantifying shallow convective processes and characterizing cloud and precipitation formation. Especially in the trade wind regions, high resolution observations are needed, for example, to evaluate the representation of shallow convective cloud parameterization in models. Synergistic retrievals using groundbased active and passive remote sensing observations can help close this observational gap, e.g., in between regular radiosonde network launch times. In clear-sky cases, lidar systems give very accurate profiles of water vapor; in cloudy conditions, however, these observational methods fail to reproduce the atmospheric state within and above the cloud layer due to signal saturation. In these cases, the approach presented in this study can help to complement the picture.

In this paper, we present the potential of a novel synergistic, optimal estimation-based retrieval approach combining microwave radiometer and dual-frequency radar observations. Specifically, we use synthetic observations of TB and DWR to quantify the synergistic benefits of combining MWR with either the Ka- and W-band radars (KaW), e.g., available at BCO, or with a novel differential absorption radar prototype (Roy et al. 2020) using frequencies of 167 and $174.8 \mathrm{GHz}(\mathrm{G} 2)$. The simulated $\mathrm{G} 2$ radar reflectivities and resulting dual-wavelength ratios show a higher sensitivity to changing water vapor conditions than the $\mathrm{KaW}$ simulations. However, the simulated observations suggest that full-cloud profiling might in reality be impaired by current G-band radar sensitivity thresholds in shallow cloud scenarios such as modeled in this study.

We retrieve the full-column absolute humidity profile as well as the LWP for a single-layered liquid cloud scenario typical for the atmospheric conditions observed at BCO, assuming full-cloud profiling. The synergistic approach combines the advantages of both instruments: the high potential of the MWR for retrieving integrated quantities such as IWV, LWP and coarse water vapor profiles throughout the column; and the high profiling potential of dual-frequency radar, providing the partial water vapor amounts between the radar range gates in the presence of backscattering targets.

Based on case study results and the statistical analysis of different water vapor conditions, we find that the combination of MWR $+\mathrm{KaW}$ only marginally increases the total retrieval information content compared to the retrieval based on pure MWR observations (3.4 vs 3.2 DFS). Within the cloud layer, the increasing ambiguity of separating liquid and water vapor impacts in the DWR signal leads to reduced DWR signal ranges for varying water vapor conditions. The addition of $\mathrm{KaW}$ radar observations to the retrieval could, however, be beneficial for deriving cloud-base and cloud-top height, partial IWV amount up to cloud base, and the LWC profile (e.g., Hogan et al. 2005; Zhu et al. 2019). The analysis could also be further expanded to drizzling clouds by combining the presented algorithm with the modified Frisch approach presented by Küchler et al. (2018).

The combination of DAR G2 and MWR, on the other hand, increases the information content on average by 1 DFS to 4.4 , particularly below and within the cloud layer. There, the radar observations provide all information for the water vapor states. The full potential of this synergy is seen above the cloud layer where the synergistic information content is enhanced compared to the MWR-only and DAR G2-only setup.

The results show sensitivity to the assumed measurement errors, particularly to the radar uncertainties. To gain the full synergistic potential of this approach, more sensitive G-band radars are needed for future applications. Increasing sensitivity, for example, through increased transmitter power, is required in order to fully profile the shallow clouds observed at BCO. Albeit, when applying the retrieval to real observations, further sources of uncertainty will have to be quantified: beam mismatching of the instruments, misalignment of the radar antennas, intercalibration discrepancies of the radars, horizontal spacing between the instruments (Küchler and Löhnert 2019), and nonuniform beam filling effects. By operating the VIPR instrument (Roy et al. 2020) at BCO in close vicinity of the HATPRO, these uncertainties could be further quantified, and the detection limits, as well as the synergistic retrieval, could be further evaluated.

This synthetic study will be expanded to more complex cloud scenarios observed at BCO. The synergistic benefit will be further analyzed for cases of double-layered liquid clouds, as well as overlying ice cirrus clouds, expanding the presented study to a larger variation of more realistic scenarios. For these cases, we expect the synergistic benefit analysis to be more complicated due to assumptions about the partitioning of LWP per cloud layer, as well as non-Rayleigh-scattering effects influencing the radar observations. In cases of multiple-layer clouds, however, we also expect the synergy to be more pronounced due to increased information content between the cloud layers.

To further customize this retrieval to typical trade wind boundary layers and enhance the synergistic effects, the effects of additional constraining tools will be analyzed: reducing retrieval states by parameterizing the profiles in sub-, in-, and above cloud; including the surface temperature and the 
assumption of a well-mixed BL under cloud base; forcing humidity saturation within the cloud layer through a simultaneous temperature profiling retrieval; using cloud-top height as a proxy for the inversion layer height; and analyzing the retrieval performance for circulation-dependent prior conditions. Further analyses will investigate the potential of including the direct inversion approach presented by Roy et al. (2020) into the synergy concept.

To overcome current G-band radar sensitivity constraints in high moisture and shallow cloud conditions such as observed in the trades, current detection limits would have to be enhanced. However, the application of this synergy concept is not limited to the trade wind region: a synergy application of MWR and current high-frequency radar instruments would be particularly beneficial in drier environments, such as at midlatitude observatories like the Jülich Observatory for Cloud Evolution (JOYCE; Löhnert et al. 2015), or in the Arctic environment. Further analyses, including the air- and spaceborne application, will also contribute to assimilation strategies in numerical weather models, as well as to both satellite calibration and product evaluation campaigns. Synergy concepts of passive and active microwave sensors such as discussed in this study will contribute to closing the current gap of continuous, high-resolution water vapor observations in the cloudy boundary layer.

Acknowledgments. This study was funded by the $\mathrm{HD}(\mathrm{CP})^{2}$ project that is funded by the German Federal Ministry of Education and Research (BMBF) within the framework program "Research for Sustainable Development (FONA)" under Grant 01 LK1502E. The author's research stay at BCO was funded by the Graduate School of Geosciences (GSGS), University of Cologne, through Grant GSGS-2019A-03. We thank Friedhelm Jansen from Max Planck Institute for Meteorology (MPI-M) for support and assistance in the measurements performed at BCO, R. Roy and A. Myagkov for their comments on current radar sensitivity potential, and M. Maahn for support with the OE library available in Maahn et al. (2020). We thank the anonymous reviewers for their improving suggestions on the manuscript.

\section{REFERENCES}

Abel, S. J., and B. J. Shipway, 2007: A comparison of cloudresolving model simulations of trade wind cumulus with aircraft observations taken during RICO. Quart. J. Roy. Meteor. Soc., 133, 781-794, https://doi.org/10.1002/qj.55.

Barrera-Verdejo, M., S. Crewell, U. Löhnert, E. Orlandi, and P. Di Girolamo, 2016: Ground-based lidar and microwave radiometry synergy for high vertical resolution absolute humidity profiling. Atmos. Meas. Tech., 9, 4013-4028, https://doi.org/ 10.5194/amt-9-4013-2016.

Battaglia, A., and P. Kollias, 2019: Evaluation of differential absorption radars in the $183 \mathrm{GHz}$ band for profiling water vapour in ice clouds. Atmos. Meas. Tech., 12, 3335-3349, https:// doi.org/10.5194/amt-12-3335-2019.

- C. D. Westbrook, S. Kneifel, P. Kollias, N. Humpage, U. Löhnert, J. Tyynelä, and G. W. Petty, 2014: G band atmospheric radars: New frontiers in cloud physics. Atmos. Meas. Tech., 7, 1527-1546, https://doi.org/10.5194/amt-7-15272014.
Cimini, D., P. W. Rosenkranz, M. Y. Tretyakov, M. A. Koshelev, and F. Romano, 2018: Uncertainty of atmospheric microwave absorption model: Impact on ground-based radiometer simulations and retrievals. Atmos. Chem. Phys., 18, 15 231-15 259, https://doi.org/10.5194/acp-18-15231-2018.

Crewell, S., and U. Löhnert, 2007: Accuracy of boundary layer temperature profiles retrieved with multifrequency multiangle microwave radiometry. IEEE Trans. Geosci. Remote Sens., $\mathbf{4 5}$, 2195-2201, https://doi.org/10.1109/TGRS.2006.888434.

Ebell, K., E. Orlandi, A. Hünerbein, U. Löhnert, and S. Crewell, 2013: Combining ground-based with satellite-based measurements in the atmospheric state retrieval: Assessment of the information content. J. Geophys. Res. Atmos., 118, 6940-6956, https://doi.org/10.1002/jgrd.50548.

—, U. Löhnert, E. Päschke, E. Orlandi, J. H. Schween, and S. Crewell, 2017: A 1-D variational retrieval of temperature, humidity, and liquid cloud properties: Performance under idealized and real conditions. J. Geophys. Res. Atmos., 122, 1746-1766, https://doi.org/10.1002/2016JD025945.

Ellis, S. M., and J. Vivekanandan, 2011: Liquid water content estimates using simultaneous S- and Ka-band radar measurements. Radio Sci., 46, RS2021, https://doi.org/10.1029/ 2010RS004361.

Foth, A., and B. Pospichal, 2017: Optimal estimation of water vapour profiles using a combination of Raman lidar and microwave radiometer. Atmos. Meas. Tech., 10, 3325-3344, https:// doi.org/10.5194/amt-10-3325-2017.

Görsdorf, U., V. Lehmann, M. Bauer-Pfundstein, G. Peters, D. Vavriv, V. Vinogradov, and V. Volkov, 2015: A 35-GHz polarimetric Doppler radar for long-term observations of cloud parameters-Description of system and data processing. J. Atmos. Oceanic Technol., 32, 675-690, https://doi.org/10.1175/ JTECH-D-14-00066.1.

Hartmann, D. L., and Coauthors, 2013: Observations: Atmosphere and surface. Climate Change 2013: The Physical Science Basis, T. F. Stocker et al., Eds., Cambridge University Press, 159-254, https://doi.org/10.1017/CBO9781107415324.008.

Held, I. M., and B. J. Soden, 2006: Robust responses of the hydrological cycle to global warming. J. Climate, 19, 5686-5699, https://doi.org/10.1175/JCLI3990.1.

Hogan, R. J., N. Gaussiat, and A. J. Illingworth, 2005: Stratocumulus liquid water content from dual-wavelength radar. J. Atmos. Oceanic Technol., 22, 1207-1218, https://doi.org/10.1175/ JTECH1768.1.

Holloway, C. E., and J. D. Neelin, 2009: Moisture vertical structure, column water vapor, and tropical deep convection. J. Atmos. Sci., 66, 1665-1683, https://doi.org/10.1175/2008JAS2806.1.

Illingworth, A. J., and Coauthors, 2007: Cloudnet: Continuous evaluation of cloud profiles in seven operational models using ground-based observations. Bull. Amer. Meteor. Soc., 88, 883-898, https://doi.org/10.1175/BAMS-88-6-883.

Jacob, M., F. Ament, M. Gutleben, H. Konow, M. Mech, M. Wirth, and S. Crewell, 2019: Investigating the liquid water path over the tropical Atlantic with synergistic airborne measurements. Atmos. Meas. Tech., 12, 3237-3254, https://doi.org/10.5194/ amt-12-3237-2019.

Küchler, N., and U. Löhnert, 2019: Radar-radiometer-based liquid water content retrievals of warm low-level clouds: How the measurement setup affects retrieval uncertainties. IEEE J. Sel. Top. Appl. Earth Obs. Remote Sens., 12, 1355-1361, https://doi.org/10.1109/JSTARS.2019.2908414.

— S. Kneifel, U. Löhnert, P. Kollias, H. Czekala, and T. Rose, 2017: A W-band radar-radiometer system for accurate and 
continuous monitoring of clouds and precipitation. J. Atmos. Oceanic Technol., 34, 2375-2392, https://doi.org/10.1175/ JTECH-D-17-0019.1.

,$- \ldots$, P. Kollias, and U. Löhnert, 2018: Revisiting liquid water content retrievals in warm stratified clouds: The modified Frisch. Geophys. Res. Lett., 45, 9323-9330, https://doi.org/ 10.1029/2018GL079845.

Lebsock, M. D., K. Suzuki, L. F. Millán, and P. M. Kalmus, 2015: The feasibility of water vapor sounding of the cloudy boundary layer using a differential absorption radar technique. Atmos. Meas. Tech., 8, 3631-3645, https://doi.org/10.5194/ amt-8-3631-2015.

Löhnert, U., S. Crewell, C. Simmer, and A. Macke, 2001: Profiling cloud liquid water by combining active and passive microwave measurements with cloud model statistics. J. Atmos. Oceanic Technol., 18, 1354-1366, https://doi.org/10.1175/ 1520-0426(2001)018<1354:PCLWBC>2.0.CO;2.

,-- , and,- 2004 : An integrated approach toward retrieving physically consistent profiles of temperature, humidity, and cloud liquid water. J. Appl. Meteor., 43, 1295-1307, https://doi.org/10.1175/1520-0450(2004)043<1295:AIATRP> 2.0.CO;2.

— D. D. Turner, and S. Crewell, 2009: Ground-based temperature and humidity profiling using spectral infrared and microwave observations. Part I: Simulated retrieval performance in clear-sky conditions. J. Appl. Meteor. Climatol., 48, 1017-1032, https://doi.org/10.1175/2008JAMC2060.1.

— , and Coauthors, 2015: JOYCE: Jülich Observatory for Cloud Evolution. Bull. Amer. Meteor. Soc., 96, 1157-1174, https:// doi.org/10.1175/BAMS-D-14-00105.1.

Maahn, M., D. D. Turner, U. Löhnert, D. J. Posselt, K. Ebell, G. G. Mace, and J. M. Comstock, 2020: Optimal estimation retrievals and their uncertainties: What every atmospheric scientist should know. Bull. Amer. Meteor. Soc., 101, E1512E1523, https://doi.org/10.1175/BAMS-D-19-0027.1.

Maschwitz, G., U. Löhnert, S. Crewell, T. Rose, and D. D. Turner, 2013: Investigation of ground-based microwave radiometer calibration techniques at $530 \mathrm{hPa}$. Atmos. Meas. Tech., 6, 2641-2658, https://doi.org/10.5194/amt-6-2641-2013.

Mech, M., M. Maahn, S. Kneifel, D. Ori, E. Orlandi, P. Kollias, V. Schemann, and S. Crewell, 2020: PAMTRA 1.0: The Passive and Active Microwave radiative Transfer tool for simulating radiometer and radar measurements of the cloudy atmosphere. Geosci. Model Dev., 13, 4229-4251, https://doi.org/10.5194/gmd13-4229-2020.

Miles, N. L., J. Verlinde, and E. E. Clothiaux, 2000: Cloud droplet size distributions in low-level stratiform clouds. J. Atmos. Sci., 57, 295-311, https://doi.org/10.1175/15200469(2000)057<0295:CDSDIL>2.0.CO;2.

Millán, L., M. Lebsock, N. Livesey, and S. Tanelli, 2016: Differential absorption radar techniques: Water vapor retrievals. Atmos. Meas. Tech., 9, 2633-2646, https://doi.org/10.5194/amt-92633-2016.

Nehrir, A. R., and Coauthors, 2017: Emerging technologies and synergies for airborne and space-based measurements of water vapor profiles. Surv. Geophys., 38, 1445-1482, https:// doi.org/10.1007/s10712-017-9448-9.

Nuijens, L., I. Serikov, L. Hirsch, K. Lonitz, and B. Stevens, 2014: The distribution and variability of low-level cloud in the North Atlantic trades. Quart. J. Roy. Meteor. Soc., 140, 2364-2374, https://doi.org/10.1002/qj.2307.
Pincus, R., D. Winker, S. Bony, and B. Stevens, Eds., 2018: Shallow Clouds, Water Vapor, Circulation, and Climate Sensitivity. Space Sciences Series of ISSI, Springer Interna tional Publishing, 396 pp., https://doi.org/10.1007/978-3319-77273-8.

Rodgers, C. D., 2000: Inverse Methods for Atmospheric Sounding: Theory and Practice. World Scientific, $238 \mathrm{pp}$.

Rose, T., S. Crewell, U. Löhnert, and C. Simmer, 2005: A network suitable microwave radiometer for operational monitoring of the cloudy atmosphere. Atmos. Res., 75, 183-200, https:// doi.org/10.1016/j.atmosres.2004.12.005.

Roy, R. J., M. Lebsock, L. Millán, and K. B. Cooper, 2020: Validation of a G-band differential absorption cloud radar for humidity remote sensing. J. Atmos. Oceanic Technol., 37, 1085-1102, https://doi.org/10.1175/JTECH-D-19-0122.1.

Schnitt, S., E. Orlandi, M. Mech, A. Ehrlich, and S. Crewell, 2017: Characterization of water vapor and clouds during the Next-Generation Aircraft Remote Sensing for Validation (NARVAL) south studies. IEEE J. Sel. Top. Appl. Earth Obs. Remote Sens., 10, 3114-3124, https://doi.org/10.1109/ JSTARS.2017.2687943.

Schröder, M., and Coauthors, 2019: The GEWEX water vapor assessment: Overview and introduction to results and recommendations. Remote Sens., 11, 251, https://doi.org/10.3390/ rs11030251.

Sherwood, S. C., R. Roca, T. M. Weckwerth, and N. G. Andronova, 2010: Tropospheric water vapor, convection, and climate. Rev. Geophys., 48, RG2001, https://doi.org/10.1029/2009RG000301.

Stankov, B. B., 1998: Multisensor retrieval of atmospheric properties. Bull. Amer. Meteor. Soc., 79, 1835-1854, https://doi.org/ 10.1175/1520-0477(1998)079<1835:MROAP > 2.0.CO;2.

Stevens, B., and Coauthors, 2016: The Barbados Cloud Observatory: Anchoring investigations of clouds and circulation on the edge of the ITCZ. Bull. Amer. Meteor. Soc., 97, 787-801, https:// doi.org/10.1175/BAMS-D-14-00247.1.

- H. Brogniez, C. Kiemle, J.-L. Lacour, C. Crevoisier, and J. Kiliani, 2017: Structure and dynamical influence of water vapor in the lower tropical troposphere. Surv. Geophys., 38, 1371-1397, https://doi.org/10.1007/s10712-017-9420-8.

Tian, L., G. M. Heymsfield, L. Li, and R. C. Srivastava, 2007: Properties of light stratiform rain derived from $10-$ and $94-\mathrm{GHz}$ airborne Doppler radars measurements. J. Geophys. Res., 112, D11211, https://doi.org/10.1029/2006JD008144.

Turner, D. D., and U. Löhnert, 2014: Information content and uncertainties in thermodynamic profiles and liquid cloud properties retrieved from the ground-based Atmospheric Emitted Radiance Interferometer (AERI). J. Appl. Meteor. Climatol., 53, 752-771, https://doi.org/10.1175/JAMC-D-13-0126.1.

Wagner, T. J., P. M. Klein, and D. D. Turner, 2019: A new generation of ground-based mobile platforms for active and passive profiling of the boundary layer. Bull. Amer. Meteor. Soc., 100, 137-153, https://doi.org/10.1175/BAMS-D-17-0165.1.

Westwater, E. R., S. Crewell, and C. Mätzler, 2004: A review of surface-based microwave and millimeter-wave radiometric remote sensing of the troposphere. URSI Radio Sci. Bull., 2004, 59-80, https://doi.org/10.23919/URSIRSB.2004.7909438.

Zhu, Z., K. Lamer, P. Kollias, and E. E. Clothiaux, 2019: The vertical structure of liquid water content in shallow clouds as retrieved from dual-wavelength radar observations. J. Geophys. Res. Atmos., 124, 14 184-14197, https://doi.org/10.1029/2019JD031188. 